\title{
Topical intraocular pressure therapy effects on pregnancy
}

This article was published in the following Dove Press journal:

Clinical Ophthalmology

5 October 2012

Number of times this article has been viewed

\author{
Carmen Mendez-Hernandez \\ Julian Garcia-Feijoo \\ Federico Saenz-Frances \\ Enrique Santos-Bueso \\ Jose Maria Martinez-de-la- \\ Casa
}

Alicia Valverde Megias

Ana M Fernández-Vidal

Julian Garcia-Sanchez

Ophthalmology Department, Hospital Clinico San Carlos de Madrid, Madrid, Spain

Correspondence: Carmen Mendez-

Hernandez

Glaucoma Department, Hospital Clínico

San Carlos de Madrid, C/Professor

Martin Lagos, S/N, 28040 Madrid, Spain

Tel +34 9l 3303977

Fax +34 9| $330396 \mid$

Email cdmendezh@gmail.com
Purpose: To assess the course of intraocular pressure (IOP), visual field progression, and adverse effects of antiglaucoma medication used during pregnancy.

Methods: Thirteen eyes of eight patients with glaucoma were examined. Their clinical records were reviewed to compare IOP, number of medications, and visual field indices (VFI) before, during, and after pregnancy using a two-tailed paired $t$-test.

Results: In seven (87.5\%) of the eight patients, no disease progression was observed. IOP $(\mathrm{mmHg})$ remained stable (baseline $17.3 \pm 3.6$; first trimester $17.4 \pm 5.2, P=0.930$; second trimester $18.1 \pm 4.7, P=0.519$; third trimester $20.2 \pm 8.7, P=0.344$; and postpartum $21.5 \pm 7.6$, $P=0.136)$. The mean number of glaucoma treatments fell from $1.7 \pm 0.52$ before pregnancy to $0.83 \pm 0.75(P=0.04)$ in the second and third trimesters. In one patient, IOP increased during pregnancy and there was further visual field loss. In the only patient kept on fixed combination timolol-dorzolamide therapy throughout pregnancy, labor was induced because of delayed intrauterine growth.

Conclusions: No changes in IOP and VFI were detected in most patients despite a reduction in the number of hypotensive agents required. Delayed intrauterine growth in one patient under fixed combination timolol-dorzolamide treatment was observed whereas no other adverse effects were detected.

Keywords: intraocular pressure, antiglaucoma medication, glaucoma, pregnancy, breast-feeding, adverse effects

\section{Introduction}

Glaucoma progression during pregnancy varies among individuals ${ }^{1}$ and many ophthalmologists are uncertain about the safest medical treatment during pregnancy. $^{2}$

\section{Material and methods}

Eight women with glaucoma were followed at the glaucoma department of our hospital during their pregnancy. All pregnancies took place in the years between 2002 and 2010. By reviewing the clinical records, baseline, pregnancy, and postpartum intraocular pressure (IOP), glaucoma medication, and visual field indices (VFI), mean defect (MD), and loss variance (LV), (tendency-oriented perimetry; G1-TOP strategy, Octopus 1-2-3 perimeter Haag-Streit AG, Bern, Switzerland) were recorded and compared using a two-tailed paired $t$-test. Visual field loss progression was defined as an $\mathrm{MD}$ increase of at least $5 \mathrm{~dB}$ or the appearance of a new glaucomatous scotoma. 


\section{Results}

Thirteen eyes of eight women with the following types of glaucoma: congenital glaucoma (3), developmental glaucoma (2), postkeratoplasty glaucoma (1), pigmentary glaucoma (1), and bilateral ocular hypertension (1) were included in the study. Table 1 provides data on glaucoma type, age at the time of pregnancy, and surgical procedures before pregnancy.

All patients had glaucoma in both eyes with the exception of patients 2 and 4, who only had glaucoma in the right eye, and patient 7 , who had suffered a left-eye evisceration as a child due to perforating trauma. Thus, IOP measurements were made in 13 eyes of the eight patients. Moreover, visual field testing was not possible in patients 5,6 , and 7 because of low visual acuity (VA) (counting fingers or less) in one eye. Accordingly, the visual field data correspond only to 10 of the 13 eyes examined. Table 2 provides the data recorded for VA, IOP, the medications used during pregnancy, and visual field loss progression.

Before pregnancy, the mean IOP was $17.3 \pm 3.6 \mathrm{mmHg}$ and rose to $17.4 \pm 5.2(P=0.930), 18.1 \pm 4.7(P=0.519)$, $20.2 \pm 8.7(P=0.344)$ and $21.5 \pm 7.6(\mathrm{P}=0.136) \mathrm{mmHg}$ during the first, second, and third trimester, and postpartum, respectively.

No differences were detected in the $\operatorname{MD}(P=0.249)$ or LV $(P=0.463)$ before and after pregnancy.

The mean number of IOP-lowering medications fell from $1.7 \pm 0.52$ before pregnancy to $0.83 \pm 0.75(P=0.04)$ in the second and third trimesters and was $1.17 \pm 1.7$ postpartum.

In patient 2, IOP increased during pregnancy $(44 \mathrm{mmHg}$ in the third trimester) and there was progression of visual field loss in the right eye. This primagravida woman was carrying twins, and had been prescribed total bed rest due to a risk of premature birth. She could not visit our center during the third trimester and went into spontaneous labor in week 32. After Caesarean section (C-section) due to twin babies, she underwent a trabeculectomy, which achieved good control of pressure (IOP was $14 \mathrm{mmHg}$ with timolol maleate 3 months after surgery).

Latanoprost was used, alone or in combination, for 3 months in two women (patients 4 and 8) who did not notify their state until second trimester. After that period, latanoprost was discontinued, since there is still insufficient evidence to consider this drug safe. ${ }^{3}$

Pregnancies were full-term in seven of the eight women. Deliveries were vaginal in five of the eight women; in one of them forceps were used. In patient 6, labor was induced in gestation week 36 and baby was delivered by $\mathrm{C}$-section because of delayed intrauterine growth. This was the only patient kept on fixed combination timolol-dorzolamide therapy throughout pregnancy.

Patients 2 and 4 underwent $\mathrm{C}$-sections due to twin pregnancies.

Six patients required postpartum ocular hypotensive treatment. Of these, five (Patients 3, 4, 6, 7, and 8) decided to continue breastfeeding and were instructed to occlude the nasolacrimal duct with a fingertip for 5 minutes after eye drop instillation to minimize systemic absorption. ${ }^{4}$

\section{Discussion}

The present study is the first to document both the course and outcome of labor in pregnant women receiving glaucoma medication and followed in the same center.

In seven of our eight patients $(87.5 \%)$ the disease remained stable throughout pregnancy. Six of eight women required medication during pregnancy to control IOP. The most commonly used medication was timolol.

Delayed intrauterine growth in the only patient under fixed combination timolol-dorzolamide treatment was observed. There have been several reports of fetal complications from topical beta-blockers including bradycardia and arrhythmia ${ }^{5}$ although case reports have also described the use of these drops throughout pregnancy without any

Table I Glaucoma type, age at the time of pregnancy, and surgical procedures before pregnancy

\begin{tabular}{llll}
\hline Patient & Age & Glaucoma type & Prior surgery \\
\hline $\mathrm{I}$ & 33 & Ocular hypertension OU & None \\
2 & 36 & Developmental glaucoma OD & Trabeculectomy $(\mathrm{n}=2)$ \\
3 & $3 \mathrm{I}$ & Developmental glaucoma OU & Trabeculectomy $(\mathrm{OD} \mathrm{n}=2 ;$ OS $\mathrm{n}=\mathrm{I})$ \\
4 & 30 & Post-keratoplasty glaucoma OD & Penetrating keratoplasty $(\mathrm{n}=\mathrm{I})$, cataract extraction $(\mathrm{n}=\mathrm{I})$, Ahmed valve $(\mathrm{n}=\mathrm{I})$, \\
5 & $\mathrm{I}$ & Primary congenital glaucoma OU & Goniotomy $(\mathrm{n}=\mathrm{I}$ OU), trabeculectomy $(\mathrm{n}=\mathrm{I}$ OS), keratoplasty $(\mathrm{n}=2$ OS), \\
6 & 29 & Primary congenital glaucoma OU & Trabeculectomy $(\mathrm{OD} \mathrm{n}=3 ;$ OS $\mathrm{n}=2)$, Ahmed valve $(\mathrm{OD} \mathrm{n}=\mathrm{I} ;$ OS $\mathrm{n}=2)$ \\
7 & 35 & Primary congenital glaucoma OU & Trabeculectomy $(\mathrm{OU} \mathrm{n}=3)$, cataract extraction OU, evisceration OD \\
8 & 34 & Pigmentary glaucoma OU & Trabeculectomy $(\mathrm{OU} \mathrm{n}=\mathrm{I})$
\end{tabular}

Abbreviations: OD, right eye; OS, left eye; OU, both eyes. 


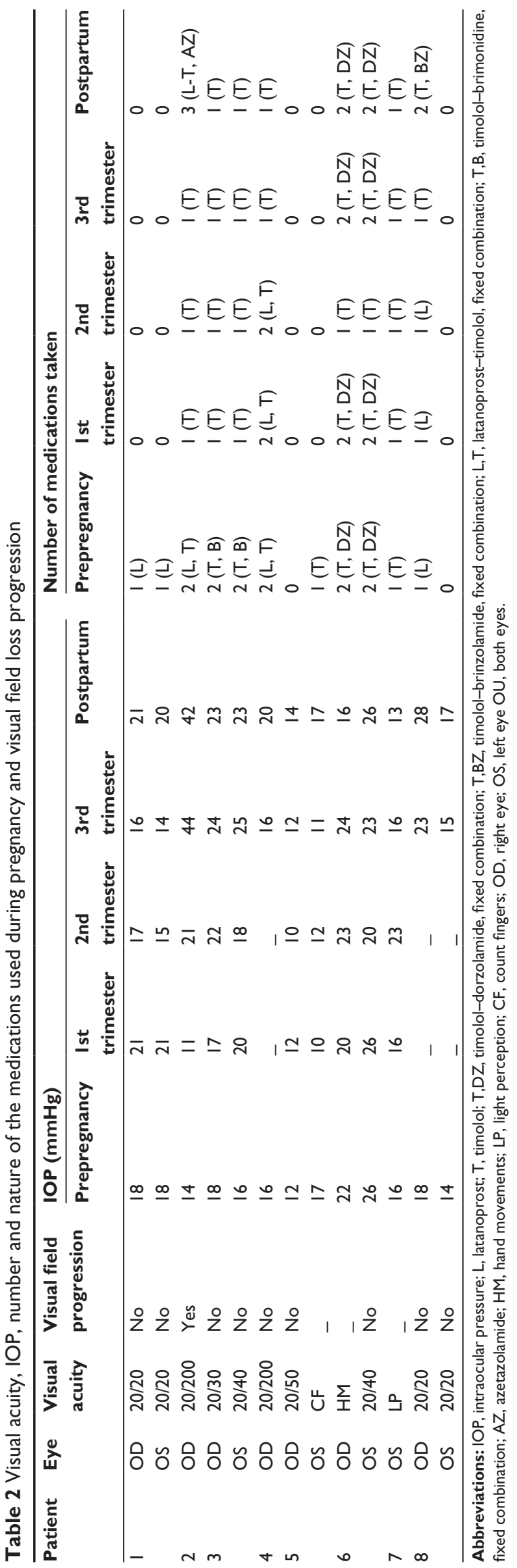

adverse effects. ${ }^{1}$ Use of acetazolamide during late pregnancy has been associated with sacrococcygeal teratoma and renal tubular acidosis in the newborn, ${ }^{6,7}$ however, there are no reported cases of adverse effects during pregnancy from topical carbonic anhydrase inhibitors.

Delayed intrauterine growth has not been described as an adverse effect of beta-blockers or carbonic anhydrase inhibitors during pregnancy although high doses of dorzolamide and brinzolamide have been reported to reduce weight gain in the offspring of lactating rats. ${ }^{8,9}$

In conclusion, good glaucoma control was achieved in most of our patients despite a reduction in the number of hypotensive agents required. Delayed intrauterine growth in one patient under fixed combination timolol-dorzolamide treatment was observed. No other adverse effects were detected neither in our patients nor in their newborns.

\section{Disclosures}

Each author declares that he or she has no commercial associations (eg, consultancies, stock ownership, equity interest, patent/licensing arrangements, etc) that might pose a conflict of interest in connection with this work. No financial support was received for this work.

\section{References}

1. Brauner SC, Chen TC, Hutchinson BT, Chang MA, Pasquale LR, Grosskreutz CL. The course of glaucoma during pregnancy: a retrospective case series. Arch Ophthalmol. 2006;124:1089-1094.

2. Vaideanu D, Fraser S. Glaucoma management in pregnancy: a questionnaire survey. Eye. 2007;21:341-343.

3. De Santis M, Lucchese A, Carducci B, Cavalieri A, De Santis L, Merota A. Latanoprost exposure in pregnancy. Am J Ophthalmol. 2004;138: 305-306.

4. Johnson SM, Martinez M, Freedman S. Management of glaucoma in pregnancy and lactation. Surv Ophthalmol. 2001;45:449-454.

5. Wagenvoort AM, van Vugt JM, Sobotka M, van Geijn HP. Topical timolol therapy in pregnancy: is it safe for the fetus? Teratology. 1998;58: $258-262$.

6. Ozawa H, Azuma E, Shindo K, Higashigawa M, Mukouhara R, Komada Y. Transient renal tubular acidosis in a neonate following transplacental acetazolamide. Eur J Pediatr. 2001;160:321-322.

7. Worsham F Jr, Beckham EN, Mitchell EH. Sacrococcygeal teratoma in a neonate. JAMA. 1978;240:251-252.

8. Alcon Ophthalmics. Manufacturer's Information: Azopt Product Monograph. Fort Worth, TX: Alcon Ophthalmics; 1998.

9. Merck and Co, Inc. Manufacturer's Information: Trusopt Product Monograph. West Point, PA: Merck and Co, Inc; 1999. 


\section{Publish your work in this journal}

Clinical Ophthalmology is an international, peer-reviewed journal covering all subspecialties within ophthalmology. Key topics include: Optometry; Visual science; Pharmacology and drug therapy in eye diseases; Basic Sciences; Primary and Secondary eye care; Patient Safety and Quality of Care Improvements. This journal is indexed on
PubMed Central and CAS, and is the official journal of The Society of Clinical Ophthalmology (SCO). The manuscript management system is completely online and includes a very quick and fair peer-review system, which is all easy to use. Visit http://www.dovepress.com/ testimonials.php to read real quotes from published authors. 